\title{
Dealing with a misdeployed esophageal stent placed for variceal bleeding
}

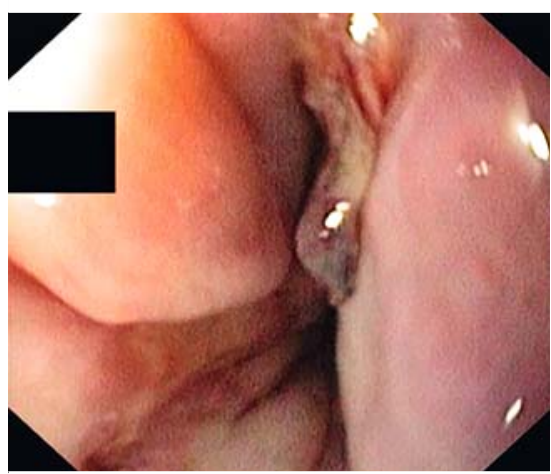

- Fig. 1 Endoscopic view showing the ligation-induced ulcer.

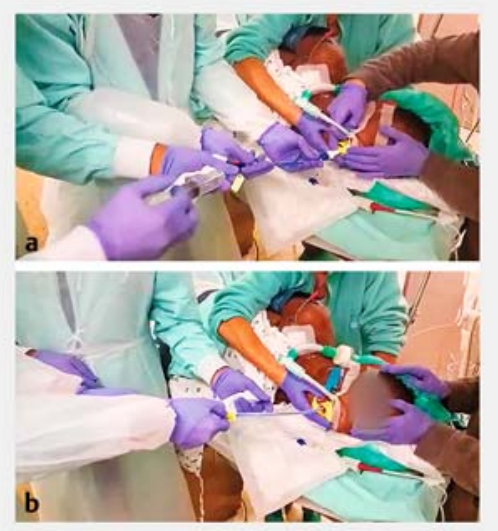

- Fig. 2 Photographs of the endoscopic procedure showing: a balloon inflation in the delivery system of the stent; $\mathbf{b}$ the delivery system being pulled back.

A 54-year-old man with hepatitis $C$ and alcohol-related Child-Pugh C cirrhosis had refractory ascites. He underwent band ligation of large esophageal varices because of his intolerance of beta blockers. Four bleeding episodes from ligation-induced ulcers occurred and an SXElla Danis fully covered self-expanding metal stent (SEMS) was placed during the last of these episodes ( $>$ Fig. 1 and - Fig. 2). On endoscopic evaluation, the distal end of the stent was proximal to the gastroesophageal junction and there was major bleeding occurring in the dis-

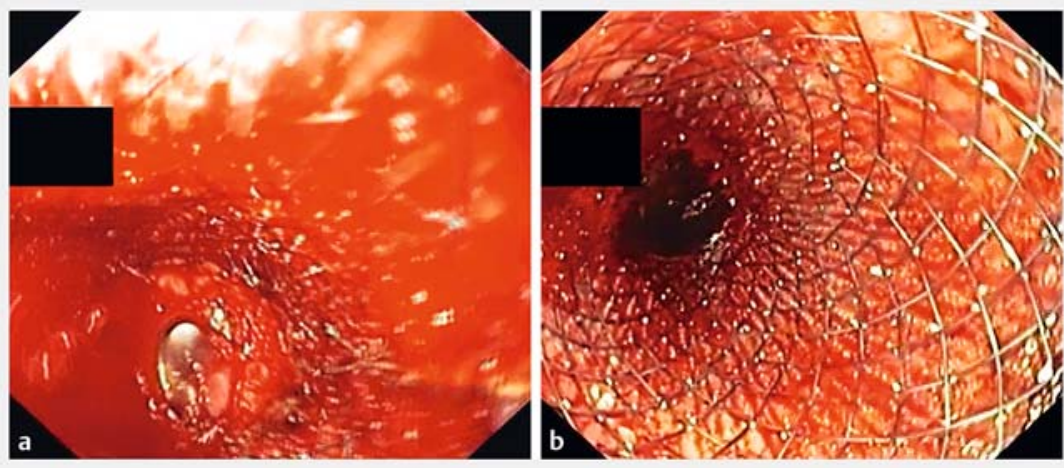

Fig. 3 Endoscopic views showing: a major bleeding after initial stent deployment; $\mathbf{b}$ the final appearance after distal repositioning of the stent.

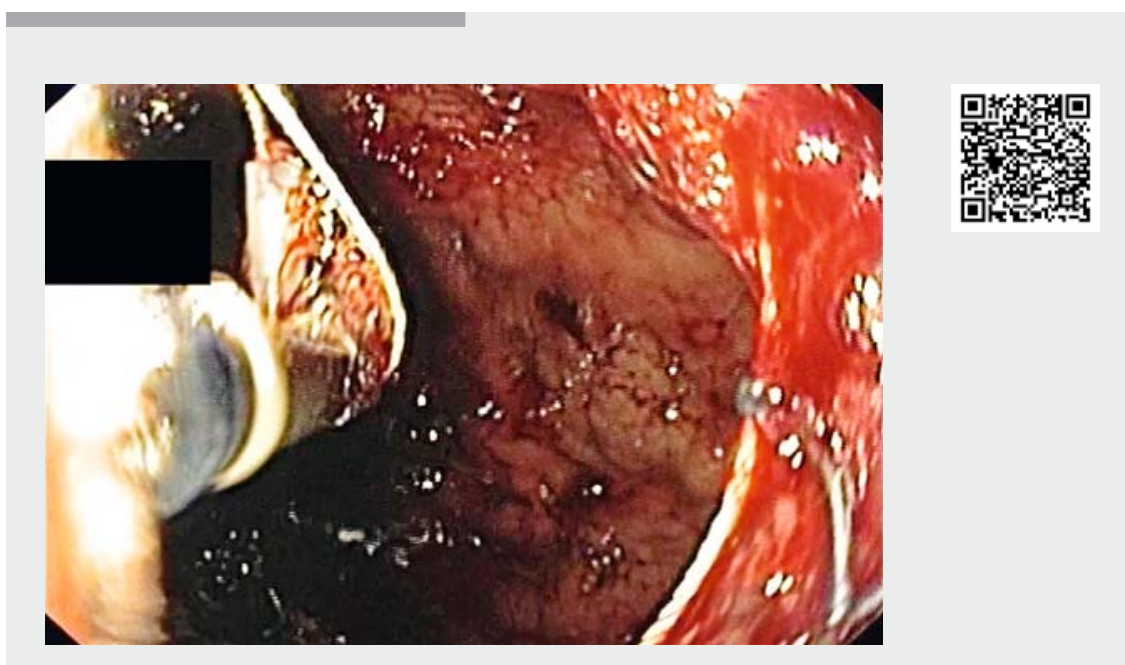

$\checkmark$ Video 1 Repositioning of a misdeployed esophageal stent placed for variceal bleeding.

tal, non-covered esophagus ( $\$$ Fig.3a) but, after sclerosant injection, the flow of blood diminished. The retrieval stent loop was grasped, which allowed slight constriction and distal movement of the stent, which resulted in adequate coverage of the distal esophagus and control

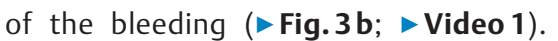
The stent was later removed after a transjugular intrahepatic portosystemic shunt (TIPS) had been placed.

Refractory esophageal variceal bleeding can be addressed by balloon tamponade, insertion of a SEMS, and/or a rescue TIPS. SEMSs are considered efficacious in this setting, usually allowing more time in place with fewer adverse events when compared with balloon tamponade [13].

We re-evaluated this adverse event and found two possible explanations. One was related to the fact that the dedicated balloon was inflated with $100 \mathrm{~mL}$ of air, according to the manufacturer instructions provided. After further investigation, we encountered an alternative 
option of filling it with $180 \mathrm{ml}$. We believe that, if the balloon had been inflated with this volume, the stent would perhaps have been deployed in the correct location as it would not have been possible to pull it upwards in the esophagus prior to its delivery. Another possible reason for this event could have been early pulling of the delivery system before complete emptying of the balloon, which also could have been responsible for pulling the stent proximally.

We report a rare life-threatening adverse event and demonstrate that it is possible to reposition a misdeployed stent successfully in the acute setting of variceal bleeding.

Endoscopy_UCTN_Code_TTT_1AO_2AD

\section{Competing interests}

The authors declare that they have no conflict of interest.

\section{The authors}

Ricardo Küttner-Magalhães ${ }^{1}$, Eduardo

Rodrigues-Pinto ${ }^{2}$, Marta Lemos-Rocha ${ }^{1}$,

Emanuel Dias², Cláudia Pinto ${ }^{1,3}$, José Manuel

Ferreira ${ }^{1}$, Isabel Pedroto ${ }^{1}$

1 Department of Gastroenterology, Santo António Hospital, Porto University Hospital Center, Porto, Portugal

2 Department of Gastroenterology, São João University Hospital Center, Porto, Portugal

3 Department of Gastroenterology, Oncology Portuguese Institute of Porto, Porto, Portugal

\section{Corresponding author}

\section{Ricardo Küttner-Magalhães, MD}

Largo Prof. Abel Salazar, 4099-001 Porto, Portugal

rkuttner@gmail.com

\section{References}

[1] de Franchis R. Expanding consensus in portal hypertension: Report of the Baveno VI Consensus Workshop: Stratifying risk and individualizing care for portal hypertension. J Hepatol 2015; 63: 743-752

[2] Marot A, Trépo E, Doerig C et al. Systematic review with meta-analysis: self-expanding metal stents in patients with cirrhosis and severe or refractory oesophageal variceal bleeding. Aliment Pharmacol Ther 2015; 42 : $1250-1260$
[3] Pfisterer N, Riedl F, Pachofszky T et al. Outcomes after placement of a SX-ELLA oesophageal stent for refractory variceal bleeding-A national multicentre study. Liver Int 2019; 39: 290-298

Bibliography

Endoscopy 2020; 52: E450-E451

DOI 10.1055/a-1164-5942

ISSN 0013-726X

published online 12.5 .2020

(c) 2020. Thieme. All rights reserved. Georg Thieme Verlag KG, Rüdigerstraße 14, 70469 Stuttgart, Germany

\section{ENDOSCOPY E-VIDEOS}

https://eref.thieme.de/e-videos

回回 Endoscopy E-Videos is a free ry access online section, reporting 回制: on interesting cases and new techniques in gastroenterological endoscopy. All papers include a high quality video and all contributions are freely accessible online.

This section has its own submission website at https://mc.manuscriptcentral.com/e-videos 